\title{
TU/e Emphoven

\section{The influence of simulated clinical handling on the flexural and compressive strength of posterior composite restorative materials}

\author{
Citation for published version (APA): \\ Huysmans, M. C. D. N. J. M., Varst, van der, P. G. T., Lautenschlager, E. P., \& Monaghan, P. (1996). The \\ influence of simulated clinical handling on the flexural and compressive strength of posterior composite \\ restorative materials. Dental Materials, 12, 116-120. https://doi.org/10.1016/S0109-5641(96)80078-9
}

DOI:

10.1016/S0109-5641(96)80078-9

Document status and date:

Published: 01/01/1996

\section{Document Version:}

Publisher's PDF, also known as Version of Record (includes final page, issue and volume numbers)

\section{Please check the document version of this publication:}

- A submitted manuscript is the version of the article upon submission and before peer-review. There can be important differences between the submitted version and the official published version of record. People interested in the research are advised to contact the author for the final version of the publication, or visit the DOI to the publisher's website.

- The final author version and the galley proof are versions of the publication after peer review.

- The final published version features the final layout of the paper including the volume, issue and page numbers.

Link to publication

\footnotetext{
General rights

- You may freely distribute the URL identifying the publication in the public portal. follow below link for the End User Agreement:

www.tue.nl/taverne

\section{Take down policy}

If you believe that this document breaches copyright please contact us at:

openaccess@tue.nl

providing details and we will investigate your claim.
}

Copyright and moral rights for the publications made accessible in the public portal are retained by the authors and/or other copyright owners and it is a condition of accessing publications that users recognise and abide by the legal requirements associated with these rights.

- Users may download and print one copy of any publication from the public portal for the purpose of private study or research.

- You may not further distribute the material or use it for any profit-making activity or commercial gain

If the publication is distributed under the terms of Article $25 \mathrm{fa}$ of the Dutch Copyright Act, indicated by the "Taverne" license above, please 


\title{
The influence of simulated clinical handling on the flexural and compressive strength of posterior composite restorative materials
}

\author{
Marie-Charlotte D. N. J. M. Huysmans ${ }^{1}$, Paul G. T. van der Varst ${ }^{2}$, \\ Eugene P. Lautenschlager ${ }^{3}$, Peter Monaghan ${ }^{3}$
}

\author{
${ }^{1}$ TRIKON: Institute for Dental Clinical Research, Department of Cariology and Endodontology, \\ University of Nijmegen, Nijmegen, THE NETHERLANDS \\ ${ }^{2}$ Centre for Technical Ceramics, Eindhoven University of Technology, Eindhoven, THE NETHERLANDS \\ ${ }^{3}$ Division of Biological Materials, Northwestern University, Chicago, Illinois, USA
}

\begin{abstract}
Objectives. The aim of this study was to investigate the influence of clinical handling on the flexural and compressive strengths of two commercially available posterior composites.

Methods. Since the manufacturing of test specimens in a truly clinical situation presents many problems, an in vitro model was developed, consisting of a phantom-head set-up in a clinical operatory. Two composite materials, recommended for use in posterior teeth, were used: P50 APC (3M Dental Products) and Herculite XRV (Kerr, Dental Manufacturing). Beam specimens for 3-point bending tests of both materials and cylindrical specimens for compression tests of $P 50$ were made both under ideal laboratory circumstances and under simulated clinical circumstances.

Results. The difference in mean flexural strength between laboratory prepared and the quasi-clinically prepared specimens was highly significant for both composites $(p<0.002)$. The reduction in mean flexural strength for the specimens handled in a clinical manner was $15 \%$ of the flexural strength of the P50 specimens made under laboratory conditions, and the difference for Herculite XRV was $29 \%$. No difference in compressive strength could be shown between the laboratory-fabricated and the quasi-clinically made specimens of P50. Significance. The relative flexural strength of composite materials in a clinical situation may differ significantly from that predicted from mechanical properties measured in vitro.
\end{abstract}

\section{INTRODUCTION}

In order to predict the clinical performance of dental materials from data measured in vitro, the correlation between laboratory and clinical results must be good. Strength criteria, e.g., for compressive, flexural, tensile, and adhesive strengths, play an important role in the acceptance of dental restorative materials, but their relevance to clinical performance has to be reviewed constantly (Söderholm, 1991).

The main problem in predicting clinical performance is that the clinical situation differs in many aspects from the laboratory situation. Clinical factors may be expected to have an influence on the physical properties of a material. An obvious shortcoming of most in vitro tests is that they reflect only initial behavior, whereas clinical failure of materials mostly occurs after long-term functioning and is the result of mechanical, chemical and/or thermal fatigue. This problem has been addressed by recent studies of the in vitro fatigue behavior of materials and restorations (Soltészet al., 1985; Zardiackas and Bayne, 1985; Huysmanset al., 1992).

A second problem that has received little attention as yet is that laboratory tests reflect the initial properties of a material when handled under ideal circumstances and that clinical handling may result in different (less favorable) properties. In recent years, a probabilistic approach to mechanical testing has been introduced into dentistry (McCabe and Carrick, 1986). In this approach, material failure is considered to be the result of flaws within the material or structure. As the distribution of these flaws (voids, microcracks, etc.) is probabilistic in nature, strength itself is probabilistic too. The strength distribution for a certain material and test will, therefore, depend on the number and size of flaws that are incorporated within the material. Test specimens used for in vitro strength testing have been manufactured under ideal circumstances, while the clinical situation presents problems such as reduced work space, impaired vision, higher humidity, etc. These factors can result in sub-optimal material manipulation, causing a larger number and/or size of flaws. As a consequence, the strength distribution that can be achieved under clinical conditions is likely to be substantially different from the "ideal" laboratory strength, and it will be more relevant to the clinical performance of dental restorations.

The aim of this study was to investigate the influence of simulated clinical handling on the initial compressive and flexural strength distribution of two commercially available composite materials. As it is virtually impossible to manufacture test specimens in a truly clinical environment, 


\begin{tabular}{|c|c|c|}
\hline Material code & P & H \\
\hline Manufacturer & $\begin{array}{l}\text { 3M Dental Products, } \\
\text { St. Paul, MN, USA }\end{array}$ & $\begin{array}{l}\text { Kerr Dental Mfg., } \\
\text { Romulus, MI, USA }\end{array}$ \\
\hline Name/color & $\begin{array}{l}\text { P50 APC, } \\
\text { color U }\end{array}$ & $\begin{array}{l}\text { Herculite XRV, } \\
\text { color A3 }\end{array}$ \\
\hline Batch \# & 2HD4R & \#2.3140 \\
\hline Mean particle size $(\mathrm{mm})^{*}$ & 2.1 & 1.0 \\
\hline Filler content (vol\%) ${ }^{*}$ & 70.1 & 55.2 \\
\hline Resin type & BisGMA & \\
\hline \multicolumn{3}{|l|}{ * source: Willems et al., 1992} \\
\hline
\end{tabular}

an in vitro model was developed in which the clinical situation was simulated.

\section{MATERIALS AND METHODS}

Two composite materials recommended for use in posterior teeth were selected: P50 APC and Herculite XRV. Details about the materials can be found in Table 1. Rectangular beam specimens for 3-point bending tests were made from both materials. P50 was also used to make cylindrical specimens for compressive testing. All specimens were made by one experienced operator.

A pilot study was performed to test the molds and the techniques used for preparing the beam specimens. A split steel mold was used with a glass slab to cover the composite before curing. This steel mold had been used for specimen manufacturing before, and it was expected that it would yield specimens approaching ideal strength. Despite using lubrication, slight adherence of the composite to the mold was usually observed. Since this might influence strength, a new Teflon mold was used for both laboratory and simulated clinical fabrication of the specimens.

The laboratory-quality specimens were made at a workbench in an air-conditioned laboratory. All specimens within one group were made on the same day, thereby reducing variations in temperature and/or humidity. The area was well-lighted, and the operator had unhampered visual and manual access.

Laboratory-quality beam specimens were made in a rectangular Teflon mold (length $=17 \mathrm{~mm}$, height $=2 \mathrm{~mm}$, width $=2 \mathrm{~mm}$ ). The mold was bulk-filled using a syringe and a tip (Centrix Accudose, Centrix Inc., Milford, CT, USA) for high-viscosity materials. The composite was gently adapted with a flat plastic filling instrument. The mold was then placed in a light-curing chamber (Dentacolor, Kulzer \& Co., Bereich Dental, Germany) and cured for $90 \mathrm{~s}$. Immediately after curing, the specimens were removed from the mold and placed in saline $(0.9 \mathrm{wt} \%)$ and stored at $37^{\circ} \mathrm{C}$. As the composite material was not covered before curing, the top surface of the specimens was not smooth. Therefore, after $1 \mathrm{~d}$, the specimens were put into a steel mold, and the top surfaces were ground level with the mold using discs (Soflex Course, 3M Dental Products Company, St. Paul, MN, USA) without water spray cooling. The specimens were then returned to the same storage conditions for $6 \mathrm{~d}$ more.

Laboratory-quality cylindrical specimens were made in glass tubing molds (diameter $=4 \mathrm{~mm}$, height $=8 \mathrm{~mm}$ ). The molds were put on a glass slab that had been lightly coated with petroleum jelly. The composite was syringed directly from the manufacturer's bulk syringe into the mold. The composite was gently adapted with a flat plastic filling instrument, and the mold was put into the light-curing chamber for $90 \mathrm{~s}$. The specimen was placed in saline at $37^{\circ} \mathrm{C}$ with the mold still in place. Smoothing similar to that done on the 3-point bending specimens was performed after $1 \mathrm{~d}$ at both ends of the specimen, using the glass mold as a guide. The specimen was then removed from the mold and stored for $6 \mathrm{~d}$ more.

Clinical simulation for specimen preparation was effected by using a phantom-head (Columbia Dentoform, New York, NY, USA) in a dental operatory. The phantom-head was secured to the headrest of a dental chair. The same mold used for the laboratory-quality beam specimens was put into the position of the upper right first molar. A glass slab withTeflon support for the cylindrical specimens was put in the position of the upper left first molar. A rubber dam covering one quadrant was placed before making specimens of either type. As the molds were situated in the upper jaw, indirect vision was used. For the beam specimen, six increments were placed with a syringe in a diagonal direction, adapted with flat and round plastic filling instruments and cured for $30 \mathrm{~s}$ each with a curing light (Visilux 2, 3M Dental Products) (Fig. 1A). Following the curing of the last increment, the specimen was removed from the mold. The top surface was smoothed immediately in the same way as for the laboratory specimens.

For the clinical-quality cylindrical specimens, the laboratory molds were used as well. The glass slab in the phantom-head jaw was lightly lubricated and the glass cylinder placed against the support. Four horizontal increments of approximately $2 \mathrm{~mm}$ in height were applied with a syringe and adapted with a round plastic filling instrument. The first three increments were cured through the glass from two directions, $20 \mathrm{~s}$ for each direction. The final increment was cured from the top of the mold for $30 \mathrm{~s}$ (Fig. 1B). The specimen was then taken out of the mouth, smoothed at both ends, removed from the mold and placed in saline. Storage time and conditions were the same as for the laboratory specimens.

Prior to being tested, the height and width of each beam specimen, and the diameter of each cylindrical specimen, were measured with a micrometer. The beam specimens were subjected to 3-point loading ( $\operatorname{span}=12 \mathrm{~mm}$ ), in a universal testing machine (Instron Corp., Canton, MA, USA) at a crosshead speed of $0.5 \mathrm{~mm} / \mathrm{min}$. The load was simultaneously recorded on a strip chart recorder. The cylindrical specimens were fractured in a compression test under the same conditions. The flexural and compressive strength were then calculated as follows:

$$
\begin{aligned}
& \text { Flexural strength }\left(S_{\mathrm{f}}\right)=(3 \cdot \mathrm{F} \cdot \mathrm{s}) /\left(2 \cdot \mathrm{w} \cdot \mathrm{h}^{2}\right) \\
& \text { Compressive strength }\left(\mathrm{S}_{\mathrm{c}}\right)=\mathrm{F} /\left(0.25 \cdot \pi \cdot \mathrm{d}^{2}\right)
\end{aligned}
$$

where $\mathrm{F}$ is load, $\mathrm{s}$ is span; $\mathrm{w}$ is width; and $\mathrm{h}$ is height of the beam specimens, and $d$ is diameter of the cylindrical specimens. 


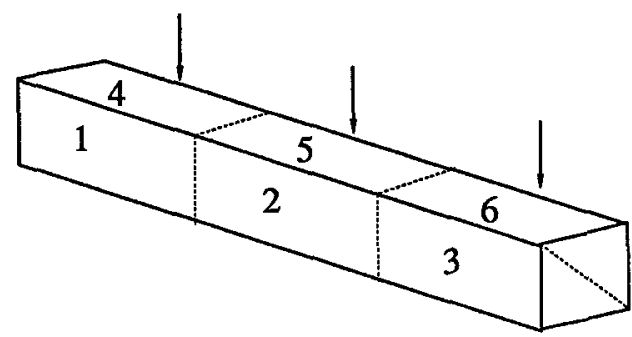

(A)

Fig. 1. Schematic drawing of the clinical-quality specimens, showing the number and location of increments. (A): 3-point bending beam, (B): compression cylinder (arrows indicate the position and direction of the curing light).

Every experimental group consisted of 30 specimens. Statistical analysis was used to compare the laboratoryquality specimens and the clinical-quality specimens. The data were analyzed using the Chi-square test, Fisher's F-test, Student's independent t-test and the Mann-Whitney U-test. Criteria for using parametric analysis for comparison of group means are that the data are normally distributed and that the variances of both groups are the same.A Chi-square test was performed for all six groups to determine whether the assumption of normal distribution should be rejected. Variances were compared per set of data using Fisher's F-test. Logtransformation of skewed distributions may improve their fit to a normal distribution, and this was tried for the groups where normality and equal variance could not be assumed. Finally, for the comparison of the means of the strength of the laboratory-quality and the clinical-quality specimens, non-parametric analysis (the Mann-Whitney U-test) was used where the assumption of normality and equal variance had to be rejected as was the case for the flexural strength tests. Parametric analysis (Student's independent t-test) was used in the case where normality and equal variance could be assumed as was the case for the compressive strength test.

\section{RESULTS}

Mean strength, standard deviation and coefficient of variation for each of the experimental groups are given in Table 2. For all experimental groups, the data could be assumed to be normally distributed, with the exception of the group of Herculite clinical-quality beam specimens (Chi-square test: $\mathrm{p}<0.05$ ). Next, the variances were compared per set using Fisher's F-test. For both materials, the laboratory-quality beam specimens and clinical-quality beam specimens had significantly different variances $(p<0.05)$. Log-transformation of the data resulted in no improvement. Therefore, it was decided to use the Mann-Whitney U-test for comparing the laboratory-quality and clinical-quality beam specimens for the 3-point bending data and Student's independent t-test for the compression data.

The difference in mean flexural strength between the laboratory-quality and the clinical-quality beam specimens was highly significant for both composites $(p<0.002)$. The reduction in mean flexural strength in the clinical-quality specimens amounted to $15 \%$ of the value for the laboratoryquality specimens of $\mathrm{P} 50$ and $29 \%$ for Herculite. No difference in compressive strength could be shown between the laboratory-quality and clinical-quality specimens.

\section{DISCUSSION}

In this study, the simulation of the clinical situation was limited by the necessity of using standard testing specimens. Some factors that are potentially important to the strength properties of restored teeth,e.g., the tooth substrate and moisture/humidity, could therefore not be included. The study included the following factors: ease of manipulation, homogeneous vs. nonhomogeneous curing, direct $v s$. indirect vision, direct vs. delayed finishing, bulk vs. incremental technique. It should be stressed that these factors were not investigated individually, but lumped together so as to compare ideal qualityvs. quality that can be realized under (simulated) clinical circumstances. Simulation of the clinical situation was only partial, so the results should be viewed as a conservative indication of the true influence of clinical handling.

Since the same molds were used for both the laboratoryquality and clinical-quality specimens, the differences that were found are very likely to be the result of the difference in handling. The flexural strength difference between the specimens prepared in these two methods was significant. This means that the expected average flexural strength of the materials when used in a clinical situation would be less than laboratory measurements would predict. Although it is not possible to separate the factors that were included in the experimental variable, it can be argued that a highly important factor was the use of the incremental technique. After taking the clinical-quality specimens from the mold, it could be seen that the adaptation of the increments to each other and to the mold was not very good. Herculite, in particular, showed lines between increments and voids (Fig. 2). These flaws were most pronounced at the lower surfaces of the specimens. In a bending test, this is the surface which undergoes the maximum tensile stress, and this relatively small volume of material is where failure is initiated. Flaws in this volume section can, therefore, be assumed to be decisive in determining strength. The fact that the strength reduction was larger for Herculite $(29 \%) v s$. P50 (15\%) supports this theory, as P50 specimens appeared to have better adaptation. This is probably the result of the lower viscosity of P50. The lower viscosity may be the result of the larger mean particle size of the material (see'Table 1). The variances in clinical-quality and laboratory-quality groups also changed. A slight decrease of the standard deviation would be expected as mean values drop, resulting in similar coefficients of variation. Table 2 shows that the opposite has occurred. This would mean that in a clinical situation, the strength of the materials is also less predictable than expected from laboratory results. Again, this was most pronounced for Herculite, showing a threefold increase in coefficient of variation.

The experimental variables had a different influence on the strength properties of P50. For compressive strength, no 


\begin{tabular}{|c|c|c|c|c|}
\hline \multicolumn{5}{|c|}{$\begin{array}{l}\text { TABLE 2: MEAN FLEXURAL AND COMPRESSIVE STRENGTHS, } \\
\text { STANDARD DEVIATIONS AND COEFFICIENTS OF VARIATION OF THE } \\
\text { EXPERIMENTAL GROUPS IN THE MAIN STUDY }\end{array}$} \\
\hline \multicolumn{5}{|c|}{ 3-Point Bending } \\
\hline Material & $\begin{array}{l}\text { Fabrication } \\
\text { Method }\end{array}$ & n & $\begin{array}{l}\text { Flexural Strength MPa } \\
\text { Mean } \pm \text { S.D. }\end{array}$ & $\begin{array}{l}\text { Coefficient } \\
\text { of Variation }\end{array}$ \\
\hline \multirow[t]{2}{*}{ P50 } & Laboratory & 30 & $139 \pm 15$ & 0.11 \\
\hline & Clinical & 30 & $118 \pm 21$ & 0.18 \\
\hline \multirow{2}{*}{ Herculite } & Laboratory & 30 & $161 \pm 14$ & 0.09 \\
\hline & Clinical & 30 & $115 \pm 32$ & 0.28 \\
\hline \multicolumn{5}{|c|}{ Compression } \\
\hline Material & $\begin{array}{l}\text { Fabrication } \\
\text { Method }\end{array}$ & n & $\begin{array}{l}\text { Compressive Strength MPa } \\
\text { Mean } \pm \text { S.D. }\end{array}$ & $\begin{array}{l}\text { Coefficient } \\
\text { of Variation }\end{array}$ \\
\hline \multirow[t]{2}{*}{ P50 } & Laboratory & 30 & $378 \pm 59$ & 0.16 \\
\hline & Clinical & 30 & $374 \pm 60$ & 0.16 \\
\hline \multicolumn{5}{|c|}{$\begin{array}{l}\text { For 3-part bending test, the comparison within materials indicated significant differences } \\
\text { due to the handling variables. (Mann-Whitney U-test: } p<0.002 \text { ) } \\
\text { For the compressive strength test, there was no significant difference between specimens } \\
\text { fabricated by the two methods (Student's independent t-test: } p=0.79 \text { ) }\end{array}$} \\
\hline
\end{tabular}

the load is much more favorable, since existing pores tend to be squeezed shut instead of acting as stress concentrators. Therefore, a rise in the number and size of flaws would not be expected to influence compressive strength to the same extent. The similarity of the results also suggests that the different curing systems did not have a major effect on the specimens.

The stress state in loaded restorations is often quite complex because it is often multi-axial in nature. Multi-axial strength tests are difficult to perform and are rarely used in dental materials testing. Even in engineering materials science, the number of different multiaxial tests that are performed is quite limited. Instead, a so-called failure criterion is often used, whereby stress states having equal probability of causing failure are considered equivalent and are therefore characterized by one single variable called "equivalent stress". Material failure can then be described by specifying a critical value of this equivalent stress. TheVon Mises equivalent stress is an example which is valid for metals. For dental composites, other equivalent stress definitions have to be used, for example the Modified Von Mises (MVM) or the Drücker-Prager (DP) equivalent stress (van der
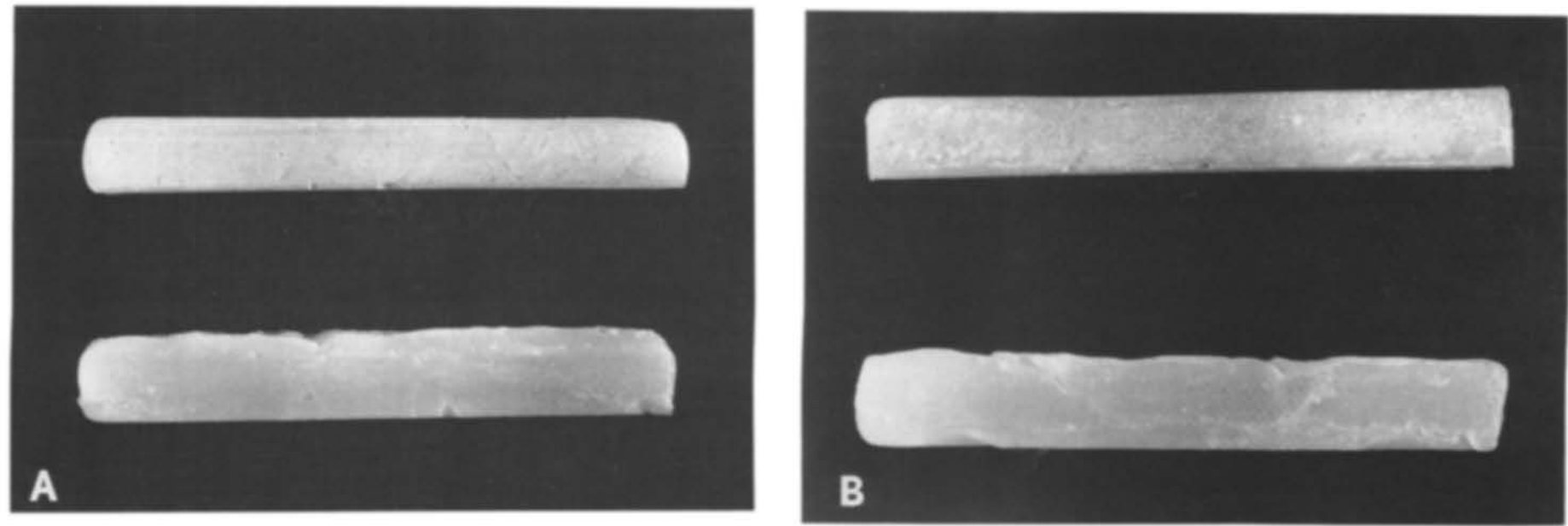

Fig. 2. Examples of beam specimens from different groups. A) P50. B) Herculite. Top is laboratory-quality, botiom is clinical-quality (smoothing of top surface not performed).

difference could be demonstrated, either in mean strength or in variance, between the laboratory-quality and clinicalquality specimens. There may be several explanations for this phenomenon. It is possible that the composite adhered slightly to the glass molds for the cylindrical specimens, thus reducing the compressive strength almost equally both types of specimens. However, no adherence to the glass was observed during the manufacturing procedures, and the mean strength of P50 in this study is comparable to that reported in the recent literature (Willemset al., 1992). The theory mentioned above, that the incremental technique was important in its influence on flexural strength, is compatible with the findings on compressive strength. In compression tests, the direction of
Varst et al., 1993). In these equivalent stress definitions, material specific parameters occur that have to be determined experimentally. For the MVM or DP equivalent stress, the material parameters can be determined using a flexural and a compressive strength test. Once these strength values are determined, the equivalent stress definition is fully specified and its critical value known. Thus, these equivalent stresses can be used to evaluate the criticality of stress states much more complex than those in the strength tests. In this study, the influence of simulated clinical handling on the flexural and compressive strength was investigated and, implicitly, the influence of simulated clinical handling on failure criteria such as MVM or DP was determined. 
Mathematical models have been formulated by van der Varst and co-workers (1991) and Huysmans (1992) that incorporate information on initial strength and mechanical fatigue characteristics of materials, restoration shape, clinical loading history, etc., to estimate mechanical lifetimes of dental restorations. It is highly important for the validity of such models that the input data have as much relevance to the clinical situation as possible. Therefore, strength distributions obtained under conditions that simulate the clinical situation should be used, rather than ideal laboratory strength distributions. Investigating the influence of processing variables on material strength has long been an accepted procedure in technology. An example of this is the influence of grinding methods on the flexural strength of ceramic materials (van den Berg and DeWith, 1993). In this respect, processing variables include all actions necessary to produce a certain product and also the restrictions inevitably accompanying the production. In this study, the same point of view is taken and applied to the production of dental restorations.

It was concluded that simulated clinical handling significantly reduced the flexural strength of posterior composites, and that this is likely to be reflected in a lower clinical strength. This strength reduction may vary between materials and may change laboratory ranking orders for strength. The clinical mechanical performance of a material which is stronger in laboratory tests may for that reason be no better or even worse than that of seemingly weaker materials.

\section{ACKNOWLEDGMENTS}

This investigation was supported in part by a Fulbright Research Grant from the Netherlands America Commission for Educational Exchange.

Received November 22, 1993 / Accepted January 30, 1996

Address correspondence and reprint requests to: Marie-Charlotte D.N.J.M. Huysmans

TRIKON: Institute for Dental Clinical Research

Department of Cariology and Endodontology

University of Nijmegen

PO Box 9101

NL-6500 HB Nijmegen, THE NETHERLANDS

\section{REFERENCES}

Huysmans MCDNeJM(1992). Mechanical failure of direct post and cores in restorative dentistry. Ph.D. dissertation, University of Nijmegen, The Netherlands.

Huysmans MCDNJM, Van derVarst PGT, Schäfer R, Peters MCRB, Plasschaert AJM, Soltész U (1992). Fatigue behaviour of direct post-and-core-restored premolars.J Dent Res 71:1145-1150.

McCabe JF, Carrick TE (1986). A statistical approach to the mechanical testing of dental materials. Dent Mater 2: 139142.

Söderholm K-JM (1991). Correlation of in vivo and in vitro performance of adhesive restorative materials: A report of the ASC MD156 task group on test methods for the adhesion of restorative materials. Dent Mater 7:7483.

Soltész U, Klaiber B, Hähnel L (1985). Wechsellastverhalten von zwei Kompositen unter Simulation physiologischer Bedingungen.Dtsch Zahnärztl Z 40:902-906.

van den Berg PHJ, De With G (1993). Strength and residual stresses of Mg-PSZ after grinding. Wear 160:301308.

van derVarst PGT, Lemmens PLM, Peters MCRB, Plasschaert AJM (1991). Estimation of the mechanical lifetime of dental restorations: Method and preliminary results. JBiomech 24:341-347.

van derVarst PGT, Brekelmans WAM, DeVree H, De Groot R (1993). Mechanical performance of a dental composite: Probabilistic failure prediction. J Dent Res 72:12491256.

Willems G, Lambrechts P,Braem M, Celis JP,Vanherle G(1992). A classification of dental composites according to their morphological and mechanical characteristics. Dent Mater 8:310-319.

Zardiackas LD, Bayne SC (1985). Fatigue characterization of nine dental amalgams. Biomaterials 6:49-54. 